\section{Cebocephaly in an infant with trisomy 18}

SUMMARY An infant who died in the perinatal period with the unusual association of trisomy 18 and cebocephaly is described. It is suggested that this association may be more common than is generally recognised because the majority of such infants are stillborn or live only briefly and often do not have chromosome studies performed.

Cebocephaly is an aetiologically heterogeneous malformation complex whose association with trisomy 13 and the $18 \mathrm{p}-, \mathrm{r}(18)$ deletion syndrome is well established, but which is distinctly uncommon in trisomy 18 (Lazjuk et al., 1976). In this paper we describe an infant with trisomy 18 who had cebocephaly, and suggest that malformations of the arrhinencephaly-holoprosencephaly type may be more common than is generally believed in trisomy 18.

\section{Case report}

This boy was the third-born child of a healthy 28year-old mother and 30-year-old father. $\mathrm{He}$ was born after 36 weeks' gestation weighing $1110 \mathrm{~g}$ and was pronounced dead at 15 minutes of age. The occipito-frontal circumference was $23 \mathrm{~cm}$, length $37 \mathrm{~cm}$, and chest circumference $21 \mathrm{~cm}$. The eyes were close set and prominent; the nasal bridge low and the nose was small with a single nostril (Fig. 1). The chin was flat, and the neck short and webbed. The testes were undescended and there was a glandular hypospadias.

Major necropsy findings included: lack of division between the cerebral hemispheres with absence of the frontal lobes, olfatory bulbs, and tracts, Type 1 tracheoesophageal fistula, a ventricular septal defect, an extralobar sequestration of the left lung supplied by a subdiaphragmatic intercostal artery and draining into the azygous vein, a Meckel's diverticulum containing heterotopic gastric mucosa and pancreatic tissue, and a single umbilical artery.

Microscopical studies, in addition, showed unexplained focal medial calcification and intimal thickening of the arteries of the neck, and prominent lymphoid aggregates in the lungs, kidneys, pancreas, and lymph nodes.

Q-banded chromosome analysis of 20 cells grown from a postmortem skin biopsy showed trisomy 18 in all cells (Fig. 2).

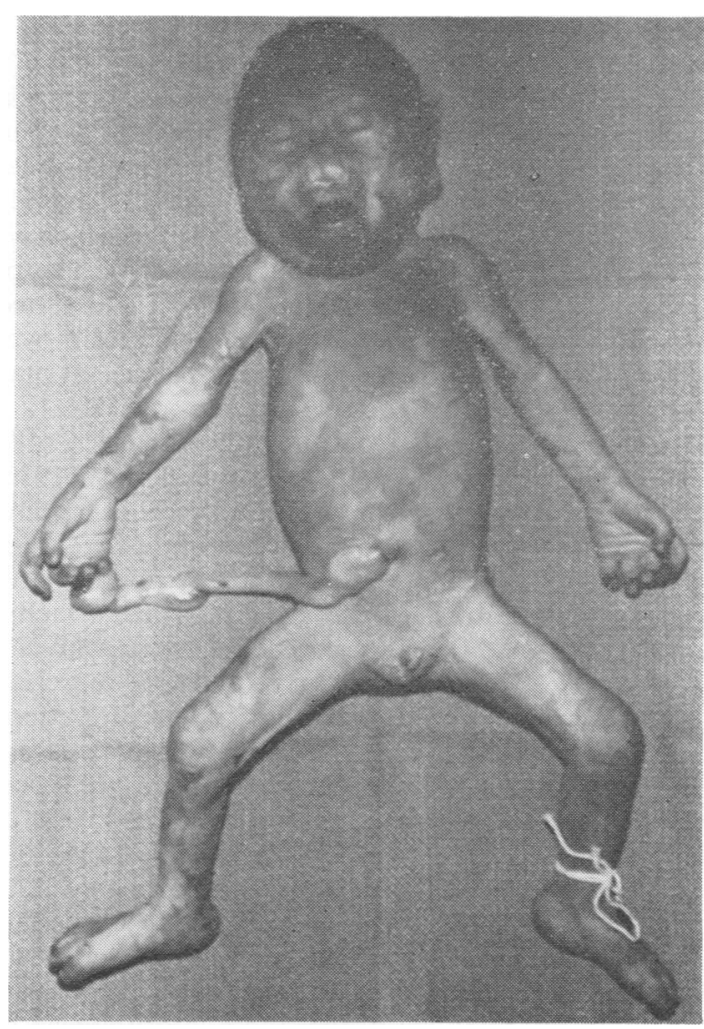

Fig. 1 Postmortem photograph of infant, illustrating cebocephaly and hypoplastic external genitalia.

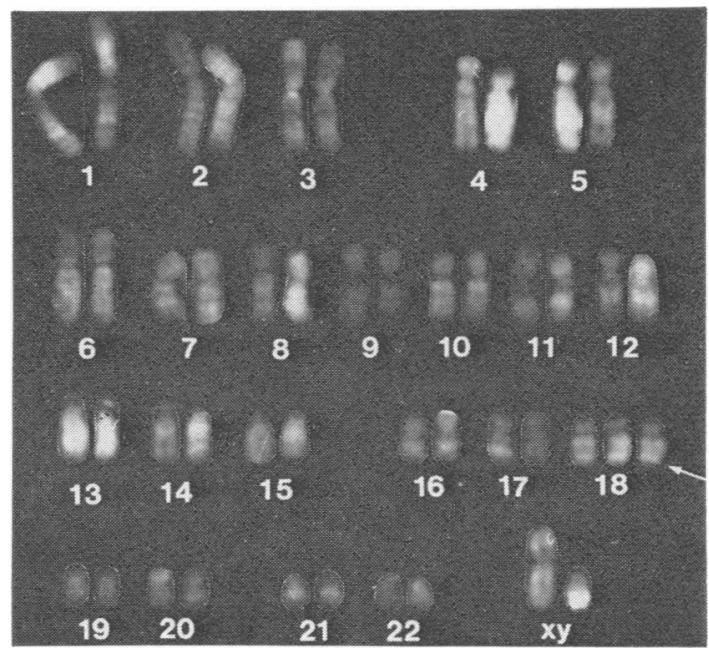

Fig. $2 Q$-banded karyotype of patient showing trisomy 18. 


\section{Discussion}

The small size for dates, cardiac and oesophageal defects observed in our patient are commonly seen in trisomy 18; however, the infant reported by Holmes et al. (1974) is the only other case of cebocephaly associated with trisomy $\mathrm{E}$ (presumed 18) of which we are aware. In a recent discussion of the genetic heterogeneity of cebocephaly, Lazjuk et al. (1976) stated that this case was the only such association in over 400 reports of trisomy 18 and suggested that it may have represented a chance occurrence.

It has been pointed out by Machin and Crolla (1974), Sutherland et al. (1974), and Kuleshov (1976) that a significant proportion of children with trisomy 18 are either stillborn or die in the immediate perinatal period. Though some of these infants have recognisable features of Edwards syndrome, Machin and Crolla (1974) emphasised that those who are stillborn or who die in the perinatal period represent the severe end of the spectrum of malformations associated with trisomy 18, are often macerated, and frequently do not have chromosome studies performed and, therefore, remain undiagnosed. It is of note that 2 of the 8 infants reported by Machin and Crolla (1974) had cerebral holospheres, and though neither of these infants had cebocephaly (G. A. Machin, 1976, personal communication), there is a consensus that cebocephaly is part of a spectrum of malformations with the same morphogenesis, ranging from defects in the prolabium and premaxilla to cyclopia (DeMyer, 1975). It is possible that patients with trisomy 18 and cebocephaly are relatively under-represented in reported series of patients with trisomy 18 as they tend to be stillborn or die in the perinatal period and are less likely to have chromosome studies performed.

We would like to thank Mrs Dianne Tucker, R. T., for her technical work, and Dr E. R. Jorundson tho referred the baby for pathological studies.

Alasdair G. W. Hunter, Manoranjan Rä, AND Claire LANGston

Division of Genetics, Departments of Pediaffics and Pathology, University of Manitoba and Hequth Sciences Centre, Winnipeg, Cand

References

DeMyer, W. (1975). Median facial malformations and their implications for brain malformations. Birth Defects: Original Article Series, Vol. XI, 7, 155-181.

Holmes, L. B., Driscoll, S., and Atkins, L. (1974). Genstic heterogeneity of cebocephaly. Journal of Medical Genesics, 11, 35-40.

Kuleshov, N. P. (1976). Chromosome anomalies of infonts dying during the perinatal period and premature newbiorn. Human Genetics, 31, 151-160.

Lazjuk, G. I., Lurie, I. W., and Nedzved, M. K. (1976). Further studies on the genetic heterogeneity of ceboceph fofy. Journal of Medical Genetics, 13, 314-318.

Machin, G. A., and Crolla, J. A. (1974). Chromosome Eonstitution of 500 infants dying during the perinatal period. Humangenetik, 23, 183-198.

Sutherland, G. R., Bauld, R., and Bain, A. D. (1974). Chromosome abnormality and perinatal death. Lancet, 1,752 .

Requests for reprints to Dr A. Hunter, Departmentof Genetics, Health Sciences Centre, 700 Willem Avenue, Winnipeg, Canada R3E OW1.

\section{Addendum}

After acceptance of this paper for publication a report appeared by Lang et al. (1976) of a stillb\&rn infant with trisomy 18 and cyclopia. This report a ids weight to our contention that a significant proportion of infants with trisomy 18 and malformations the arrhinencephaly type may go undiagnosed because of failure to carry out chromosome studieg.

\section{Reference}

Lang, A. P., Schlager, F. M., and Gardner, H. A. ( Trisomy 18 and cyclopia. Teratology, 14, 195-204.
(19.9.96). 